\title{
Review article inferior vena cava thrombosis: a case series of patients observed in Taiwan and literature review
}

\author{
Hsuan-Yu Lin ${ }^{1}$, Ching-Yeh Lin ${ }^{1}$ and Ming-Ching Shen ${ }^{1,2^{*}}$
}

\begin{abstract}
Inferior vena cava thrombosis (IVCT) is rare and can be under-recognized. However, the associated complications and mortality may be severe. We report the first case series of IVCT observed in Taiwan with a brief literature review. Eight Taiwanese patients with IVCT between May 2012 and December 2019 were enrolled in this study. Deep venous thrombosis (DVT, 8/8) and pulmonary embolism (5/8) were reported. Various risk factors were identified, including an unretrieved inferior vena cava (IVC) filter, pregnancy, surgery, presence of lupus of anticoagulants, essential thrombocythemia, antithrombin deficiency, and hemoglobin $\mathrm{H}$ disease. Of note, four of our patients experienced complete IVC thrombosis with bilateral lower extremity swelling (due to DVT) and abdominal wall superficial venous dilatation, while four other patients presented with partial IVCT and unilateral DVT. The etiology, clinical characteristics, presentations, diagnosis, and treatment of IVCT were reviewed.
\end{abstract}

Keywords: Inferior vena cava, Venous thromboembolism, Pulmonary embolism, Taiwan, Vena cava filters, Postthrombotic syndrome

\section{Background}

Inferior vena cava thrombosis (IVCT) is a clinically rare condition [1]. According to the United States National Hospital Discharge Survey, vena cava thrombosis (presumed to be predominantly IVCT) accounted for only $1.3 \%$ of all hospitalized patients who were diagnosed with venous thrombosis between 1979 and 2005 [2]. In Asia, a low incidence of IVCT is plausible, since a lower risk and incidence of venous thromboembolism (VTE) in ethnic Asian populations have been demonstrated [3] However, the true incidence of IVCT could be underestimated due to a lack of standardized detection methods and insufficient clinical awareness. Therefore, IVCT may be an under-recognized condition.

\footnotetext{
* Correspondence: 111710@cch.org.tw

'Division of Hematology/Oncology, Changhua Christian Hospital, Nanshiao St 135, Changhua City, Changhua County, Taiwan

2Department of Laboratory Medicine, Department of Internal Medicine, National Taiwan University Hospital, Taipei, Taiwan
}

Although IVCT is not commonly identified, the associated acute or chronic complications are significant and alarming. These include post-thrombotic syndrome (PTS, $90 \%$ ), venous claudication (45\%), pulmonary embolism (PE, $30 \%$ ), and venous ulceration (15\%) [4]. Furthermore, the mortality rate of IVCT has been reported to be two-fold higher than that of deep vein thromboses (DVT) confined to the lower extremities. This implies that the consequences of IVCT can be serious [5].

Since 2010, IVCT has emerged as a significant issue. The United States Food and Drug Administration (FDA) released an inferior vena cava (IVC) filter-related device safety communication that indicated a potential risk of IVC filter-related complications [6], including IVCT. The FDA also recommended that the implanting physicians and clinicians responsible for the ongoing care of patients with retrievable IVC filters should consider removing the filter as soon as protection from PE is no longer required [7]. This recommendation was made to

(C) The Author(s). 2021 Open Access This article is licensed under a Creative Commons Attribution 4.0 International License, which permits use, sharing, adaptation, distribution and reproduction in any medium or format, as long as you give appropriate credit to the original author(s) and the source, provide a link to the Creative Commons licence, and indicate if changes were made. The images or other third party material in this article are included in the article's Creative Commons licence, unless indicated otherwise in a credit line to the material. If material is not included in the article's Creative Commons licence and your intended use is not permitted by statutory regulation or exceeds the permitted use, you will need to obtain permission directly from the copyright holder. To view a copy of this licence, visit http://creativecommons.org/licenses/by/4.0/ The Creative Commons Public Domain Dedication waiver (http://creativecommons.org/publicdomain/zero/1.0/) applies to the data made available in this article, unless otherwise stated in a credit line to the data. 
reduce the risks associated with chronic indwelling IVC filters.

In this study, we collected data from eight Taiwanese patients from two medical centers diagnosed with IVCT, including two patients who presented with complications after an IVC filter was placed and unretrieved. Their primary clinical information, coexisting thrombotic risk factors, additional sites of venous thrombosis, and treatment outcomes were reported. In addition, a brief review of IVCT from the literature would be presented.

\section{Case series}

\section{Patients and methods}

Eight patients diagnosed with IVCT between May 2012 and December 2019 at Changhua Christian Hospital and National Taiwan University Hospital were included in this study. All laboratory tests and radiological imaging examinations were performed as part of routine clinical evaluations. All of our eight patients with IVCT were diagnosed by abdominal computed tomography, while their DVT were detected by compression ultrasonography. Patient demographics, presenting characteristics, additional sites of venous thrombosis, location and extent of the IVCT, treatment outcome, and related adverse events were investigated. All patients provided informed consent to participate in this study, and the study was conducted in accordance with the Declaration of Helsinki.

\section{Results}

In our report, out of the eight patients with IVCT, three were men and five were women. Their ages ranged from 30 to 54 years (median age, 35.5 years). DVT associated with unilateral lower extremity swelling was detected in four patients (in the left lower extremity in two patients, and in the right lower extremity in two patients). Bilateral lower extremity swelling was detected in the remaining four patients who also presented with dilatation of the superficial veins of the abdominal wall. Collateral circulation within the abdomen was observed in five patients. Clinical presentations, extent of IVCT, and risk factors are summarized in Table 1.

No congenital IVC anomalies were detected in our cohort. All of our eight IVCT patients had DVT, while five $(62.5 \%)$ also had PE. Prior placement of an IVC filter was found to be an important risk factor for IVCT $(25 \%)$. Other VTE predisposing risk factors, including pregnancy $(37.5 \%)$, presence of lupus anticoagulants $(37.5 \%)$, surgery $(25 \%)$, essential thrombocythemia (ET, $12.5 \%)$, antithrombin deficiency (12.5\%), and hemoglobin $\mathrm{H}$ disease (12.5\%), were observed. While three of our patients exhibited lupus anticoagulants, no one expressed anti-cardiolipin antibodies. One patient presented with no known risk factors. Four patients had more than one prothrombotic risk factor. No patient had experienced cancer or Budd-Chiari syndrome (BCS) in our study.

All patients with IVCT in this study received anticoagulants. One patient (patient 6) underwent catheterdirected mechanical thrombectomy through the right lower extremity route. However, the procedure failed as the catheter could not pass through the femoral vein thrombosis. The decision regarding which investigational methods were to be used for IVCT treatment was made by the attending physician. One patient (patient 8) developed PTS (12.5\%). No IVCT-related mortality was reported in our series.

\section{Case presentation}

The clinical presentation and characteristics of one patient with IVCT in this study are briefly described below: Patient 7 was a 38-year-old man. He experienced VTE with repeated episodes of painful swelling in his right

Table 1 Clinical presentations and characteristics of eight Taiwanese patients with inferior vena cava thrombosis

\begin{tabular}{|c|c|c|c|c|c|c|c|c|c|c|c|}
\hline \multirow{2}{*}{$\begin{array}{l}\text { Patient } \\
\text { no. }\end{array}$} & \multirow{2}{*}{$\begin{array}{l}\text { Age } \\
\text { (year) }\end{array}$} & \multirow[t]{2}{*}{ Sex } & \multicolumn{2}{|c|}{ Main clinical presentation } & \multicolumn{5}{|c|}{ Site of thrombosis } & \multirow{2}{*}{$\begin{array}{l}\text { Collaterals } \\
\text { inside the } \\
\text { abdomen }\end{array}$} & \multirow[t]{2}{*}{ Risk factors } \\
\hline & & & Swelling of LE & Dilatation of SAV & IVC & IVs & PDV & DDV & $\mathrm{PE}$ & & \\
\hline 1 & 30 & $\mathrm{~F}$ & $L+R$ & Present & IHCT & $L+R$ & $L+R$ & $L+R$ & $(+)$ & Present & ET + pregnancy \\
\hline 2 & 35 & M & $L+R$ & Present & $\mathrm{IHCT}$ & $L+R$ & $L+R$ & $(-)$ & $(+)$ & Present & LA \\
\hline 3 & 32 & $\mathrm{~F}$ & L & None & IRPT & $(-)$ & L & L & $(-)$ & None & $L A+$ pregnancy + surgery \\
\hline 4 & 36 & F & L & None & IRPT & $L$ & L & $(-)$ & $(-)$ & None & Surgery \\
\hline 5 & 54 & $\mathrm{~F}$ & $L+R$ & Present & $\operatorname{IRCT}$ & $L+R$ & $L+R$ & $L+R$ & $(-)$ & Present & Unknown \\
\hline 6 & 32 & M & $\mathrm{R}$ & None & IRPT & $\mathrm{R}$ & $\mathrm{R}$ & $\mathrm{R}$ & $(+)$ & None & AT deficiency \\
\hline 7 & 38 & M & $L+R$ & Present & IRCT & $L+R$ & $L+R$ & $(-)$ & $(+)$ & Present & LA + IVC filter \\
\hline 8 & 46 & $\mathrm{~F}$ & R & None & IRPT & $(-)$ & $\mathrm{R}$ & $\mathrm{R}$ & $(+)$ & Present & $\begin{array}{l}\text { Hb H disease + pregnancy } \\
+ \text { IVC filter }\end{array}$ \\
\hline
\end{tabular}

Clinical pictures of patients with inferior vena cava thrombosis evaluated at Changhua Christian Hospital and National Taiwan University Hospital LE lower extremity, SAV superficial abdominal wall vein, IVC inferior vena cava, IVs iliac veins, PDV proximal deep vein, DDV distal deep vein, PE pulmonary embolism, $F$ female, $M$ male, $R$ right, $L$ left, IHCT infrahepatic complete thrombosis, IRCT infrarenal complete thrombosis, IRPT infrarenal partial 
lower extremity, accompanied by upper back pain and cough. The patient was diagnosed with DVT and PE. Anticoagulant treatment was initiated. An IVC filter was placed after the second VTE event. However, 6 months after filter placement, the patient had swellings in both lower extremities. The superficial veins of the abdominal and chest walls were dilated. Filter retrieval was attempted twice but was unsuccessful. A positive result for lupus anticoagulant was the only significant finding from thrombotic screening tests. Compression ultrasonography revealed partial thrombosis in the common femoral veins, superficial femoral veins, and popliteal veins of both lower extremities. Computed tomography revealed complete thrombosis in the infrarenal IVC along with the presence of an IVC filter and blood clots within both iliac veins. Collateral circulation was also observed (Fig. 1).

\section{Literature review}

To offer a thorough understanding of IVCT, a brief review from the literature is described below. Readers are also encouraged to read other comprehensive review articles $[1,4,8]$. In addition, the findings of several previous reports of IVCT as well as our study were summarized in Table 2.

\section{Etiology}

IVCT accounts for a minority of VTE cases, with a reported incidence of $4-15 \%$ in patients with DVT [13]. In accordance with VTE, IVCT could be caused by congenital or acquired abdominal pathophysiological changes with venous blood flow turbulence or stasis consequences, combined with the presence of various prothrombotic factors predisposing to VTE. Idiopathic/primary IVCT occurs without identifiable cause. It was reported to be associated with risk factors similar to those predisposing to VTE, while hypertension or metabolic syndrome-related VTE might be involved [8]. Provoked/secondary IVCT often refers to the thrombus generated from the precedent lower extremity DVT with propagation or extension into the IVC, while cancer, surgery, infection, and oral contraceptive-related VTEs are also classified as provoked and secondary [8].

Various VTE risk factors of IVCT patients from a database registration had been investigated [9-11]. Local problems such as IVC anomalies (11.3\%) and external venous compression (11.3\%), malignancy $(17.0 \%)$ and the presence of lupus anticoagulants (10.9\%), contribute to the risk of IVC thrombosis [9]. In addition, hereditary thrombophilia, hormonal treatment in woman, and previous surgery were also reported to be common risk factors of thrombosis involving IVC [10]. Table 3 summarized the etiology reported from several previous studies.

\section{Congenital anomalies of inferior vena cava}

Congenital IVC anomalies are infrequent, with an estimated incidence of $0.3-0.6 \%$ in the general population [14]. Congenital IVC anomalies include segmental hypoplasia or aplasia of the IVC and a venous aneurysm, and are usually classified into the following three main anatomic configurations [15, 16]: (a) infrarenal type (duplicate IVC, persistent left side IVC, preaortic IVC, absence of the infrarenal IVC), (b) renal type (accessory left renal vein, retroaortic and circumaortic left renal vein), and (c) suprarenal type (absence of the hepatic IVC with azygous continuation, congenital caval stenosis or atresis, IVC membrances). Each configuration with resultant turbulent blood flow has the capacity to lead to the formation of a thrombus within IVC. Due to well-developed collaterals, congenital IVC anomalies rarely manifest as symptoms and are often incidental imaging findings. Thromboembolic symptoms might be caused by the involvement of venous collaterals, frequently deep pelvic veins or common iliac veins. In the presence of caval aberrancy, bilateral iliofemoral thrombosis was found in $66-75 \%$ of patients [17, 18], while among all of the lower limb DVT patients, bilateral iliofemoral thromboses are reported to be uncommon, accounting for fewer than $10 \%$ of cases [19]. With a reported incidence of $60-80 \%$, individuals with congenital abnormalities of the IVC are more likely to develop VTE or IVCT, particularly in younger patients $[17,18,20]$. A systemic review reported that congenital IVC anomalies, with a weighted prevalence of $6.8 \%$, could lead to a 50 - to 100 -fold increase in the risk of DVT [21].

\section{Tumors}

While the risk of VTE in cancer patients is 7-fold higher than that in non-cancer populations [22], malignancy has been reported to account for $37.5 \%$ of IVCT cases in a large observational study, demonstrating its close relationship with IVCT [2]. Diverse cancer types have been reported in patients with IVCT. The most common type is renal cell carcinoma (38\%), followed by other genitourinary tract cancer (25\%) [11]. Established mechanisms including external compression of the IVC by tumor masses, progression of malignancy into the IVC (tumor thrombus), and malignancy-related hypercoagulability, have all been highlighted. It is reported that malignancyrelated IVCT more frequently involve the suprarenal and hepatic segments of the IVC and extend more often into the right atrium than does IVCT [11]. In addition, retroperitoneal leiomyosarcoma [23], adrenal cortical carcinoma [24], and renal angiomyolipoma [25] have all been shown to be associated with IVCT. Furthermore, antineoplastic therapy, such as surgery or chemotherapy, could present prothrombotic risks contributing to VTE. 

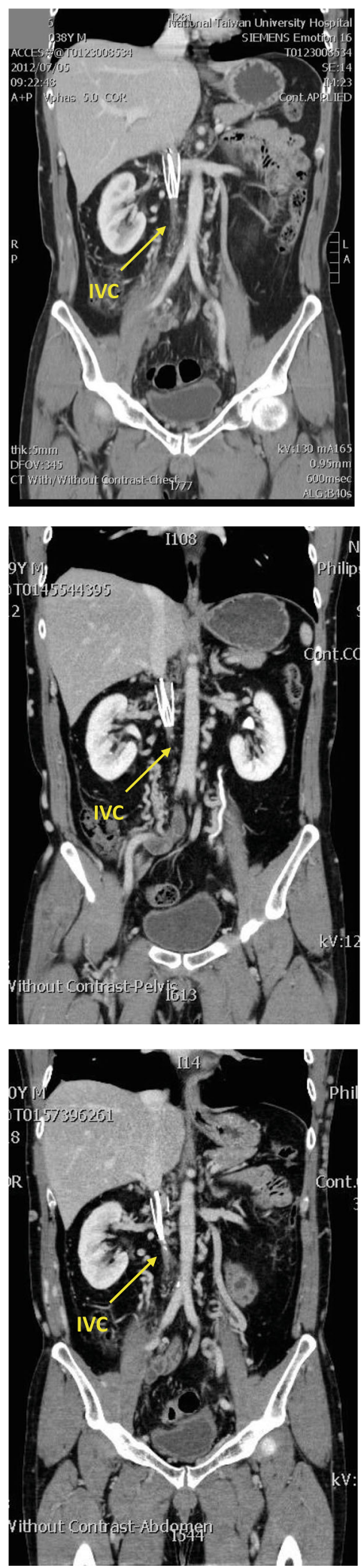

Fig. 1 Bilateral lower extremity DVT and IVC thrombosis occurred in a 38-year-old man. (A) Computed tomography demonstrated a filter bearing IVC thrombosis. In the follow-up at 21 months (B) and 33 months (C) later, computed tomography revealed a residual thrombosis. DVT, deep venous thrombosis; IVC, inferior vena cava

\section{Compression/outflow obstruction}

Direct extrinsic compression or venous outflow obstruction can trigger thrombogenesis within the IVC. Extrinsic compression may also be caused by non-tumor sources, such as aortic aneurysm, retroperitoneal fibrosis, or retroperitoneal hematoma [8].

Budd-Chiari syndrome Budd-Chiari syndrome (BCS) is characterized by the manifestations caused by hepatic venous outflow obstruction. The obstruction may occur secondarily to extrinsic compression of the hepatic vein or hepatic segment of the IVC, such as the mass effects from hepatocellular carcinoma or other lesions of the liver. Other etiology of BCS includes myeloproliferative neoplasms (MPNs), hereditary thrombophilia, pregnancy, paroxysmal nocturnal hemoglobinuria, or oral contraceptives. Additionally, membranous obstruction of the IVC at its hepatic portion, also known as obliterative hepatocavopathy, has been reported to be another etiology that has prevailed in Asia [26, 27]. Distinct pathogenesis of the "membrane" formation within the IVC at the level of the diaphragm with or without hepatic vein involvement has been proposed to be the consequences of recurrent thrombosis [26, 27]. Hepatic vein thrombosis may present as thrombogenesis provoked by a venostasis scenario, or as direct extension from a generated IVC thrombus to the intrahepatic vessels. On the other hand, IVCT may develop following the thrombotic occlusion of hepatic veins, which indicates BCS. Among patients of BCS, $20 \%$ are estimated to be associated with IVCT [28].

May-Thurner syndrome May-Thurner syndrome is noted for symptomatic left lower extremity swelling with increased risk of DVT formation. It is caused by compression of the left common iliac vein from the overlying right common iliac artery [29]. Chronic May-Thurner syndrome coexisted with DVT may lead to thrombus propagation to the IVC.

Pregnancy Pregnancy was reported to be occurred in $11.4 \%$ IVCT patients [9]. In late pregnancy, the distended uterus can compress the IVC particularly in the supine position, which leads to decreased cardiac output, hypotension, venous congestion, and stasis [30, 31], thereby increasing the risk of IVCT. The risk of VTE is increased 5- to 10-fold in pregnancy and the puerperium [32, 33], complicating 1 in 1,000 deliveries [34]. VTE is a 


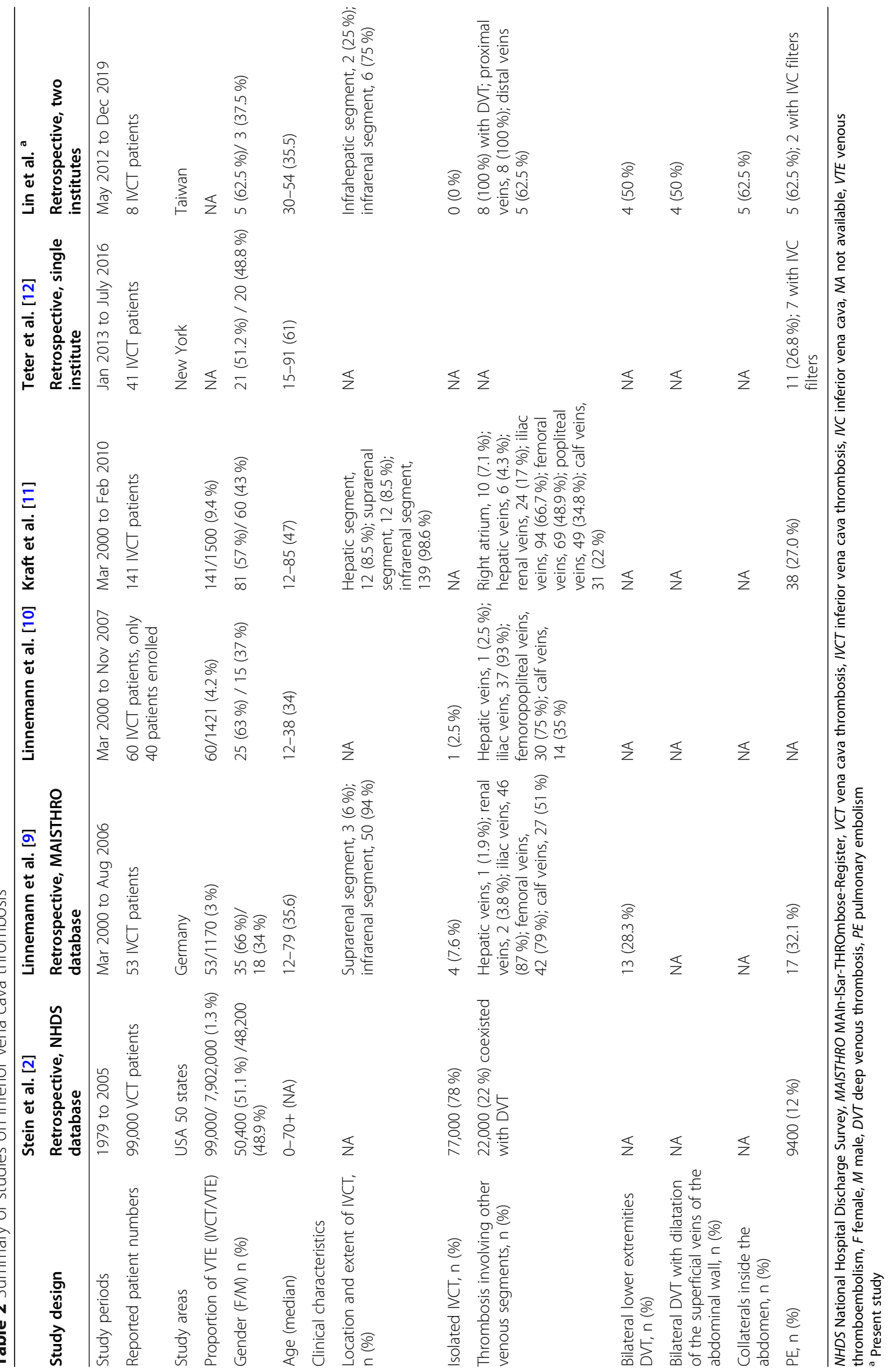


Table 3 Summary of etiology reported from studies on inferior vena cava thrombosis

\begin{tabular}{|c|c|c|c|c|c|c|}
\hline & Stein et al. [2] & $\begin{array}{l}\text { Linnemann et al. } \\
\text { [9] }\end{array}$ & Linnemann et al. [10] & Kraft et al. [11] & Teter et al. [12] & Lin et al. ${ }^{a}$ \\
\hline $\begin{array}{l}\text { Primary/ } \\
\text { unprovoked } \\
\text { IVCT }\end{array}$ & NA & NA & 16 (40 \%) & 32 (22.7\%) & NA & $1(12.5 \%)$ \\
\hline $\begin{array}{l}\text { Congenital IVC } \\
\text { anomalies, n } \\
(\%)\end{array}$ & NA & $6(11.3 \%)$ & NA & $18(12.8 \%)$ & NA & $0(0 \%)$ \\
\hline $\begin{array}{l}\text { External } \\
\text { compression, n } \\
(\%)\end{array}$ & NA & $6(11.3 \%)$ & NA & $\begin{array}{l}9 / 55(16.4 \%) \text { of } \\
\text { reported malignancy } \\
\text { related IVCT }\end{array}$ & NA & $0(0 \%)$ \\
\hline $\begin{array}{l}\text { Malignancy, } \mathrm{n} \\
(\%), \text { most } \\
\text { common } \\
\text { cancer types }\end{array}$ & $\begin{array}{l}37,000(37.4 \%), \\
\text { kidney; trachea, } \\
\text { bronchus, and } \\
\text { lung }\end{array}$ & $\begin{array}{l}9(17.0 \%) \text {, lung, } \\
\text { breast, kidney, } \\
\text { bladder, ovary, brain }\end{array}$ & $6(15 \%), N A$ & $\begin{array}{l}55(39 \%) \text {, renal, } \\
\text { ovary, testes, breast, } \\
\text { lymphoma }\end{array}$ & 17 (41.5\%), NA & $0(0 \%)$ \\
\hline $\begin{array}{l}\text { Hereditary } \\
\text { thrombophilia, } \\
\text { n (\%) }\end{array}$ & NA & $28(52.8 \%)$ & $27(51 \%)$ & 37 (38.9\%) & $4(9.8 \%)$ & $1(12.5 \%)$ \\
\hline $\begin{array}{l}\text { Antithrombin } \\
\text { deficiency, n } \\
\text { (\%) }\end{array}$ & NA & $2(3.8 \%)$ & NA & $2(1.8 \%)$ & NA & $1(12.5 \%)$ \\
\hline $\begin{array}{l}\text { Lupus } \\
\text { anticoagulants } \\
\text { /APS, n (\%) }\end{array}$ & NA & $5(10.9 \%)$ & $3(6 \%)$ & $6(5.8 \%)$ & NA & $3(37.5 \%)$ \\
\hline $\begin{array}{l}\text { Anticardiolipin } \\
\text { antibody, n (\%) }\end{array}$ & NA & $2(3.8 \%)$ & NA & NA & NA & $0(0 \%)$ \\
\hline $\begin{array}{l}\text { Pregnancy, n } \\
\text { (\%) }\end{array}$ & NA & NA & $1(4 \%)$ & $2(2.5 \%)$ & NA & $2(25 \%)$ \\
\hline Obesity, n (\%) & NA & $7(14.9 \%)$ & NA & NA & $11(26.8 \%)$ & $0(0 \%)$ \\
\hline Surgery, n (\%) & NA & $11(20.8 \%)$ & $6(15 \%)$ & $17(12.1 \%)$ & NA & $2(25 \%)$ \\
\hline IVC filters, n (\%) & NA & NA & NA & NA & $18(43.9 \%)$ & $2(25 \%)$ \\
\hline $\begin{array}{l}\text { Oral } \\
\text { contraceptives } \\
\text { / hormone } \\
\text { treatment, n } \\
\text { (\%) }\end{array}$ & NA & $13(37.1 \%)$ & $12(48 \%)$ & $25(30.9 \%)$ & $3(7.3 \%)$ & $0(0 \%)$ \\
\hline $\begin{array}{l}\text { Other risk } \\
\text { factors, n (\%) }\end{array}$ & NA & $\begin{array}{l}\text { Family history of } \\
\text { DVT, } 6(12.7 \%) ; \\
\text { inflammatory } \\
\text { disease, } 8(15.1 \%)\end{array}$ & $\begin{array}{l}\text { Inflammatory disease, } 5 \text { (13\%); } \\
\text { immobilization } 2 \text { (5\%); MPN } 0 \\
(0 \%) \text {; JAK-2 V617F mutation } 0 \\
(0 \%)\end{array}$ & $\begin{array}{l}\text { Inflammatory } \\
\text { disease, } 23(16.3 \%) \text {; } \\
\text { risk-associated DVT, } \\
109(77.3 \%)\end{array}$ & $\begin{array}{l}\text { History of prior } \\
\text { DVT, } 25(61.0 \%) ; \\
\text { smoking, } 18 \\
(43.9 \%)\end{array}$ & $\begin{array}{l}\mathrm{ET}, 1(12.5 \%) ; \\
\text { hemoglobin } \mathrm{H} \\
\text { disease, } 1 \\
(12.5 \%)\end{array}$ \\
\hline
\end{tabular}

IVCT inferior vena cava thrombosis, NA not available, IVC inferior vena cava, VTE venous thromboembolism, APS antiphopholipid antibody syndrome, MPN myeloproliferative neoplasm, DVT deep venous thrombosis, ET essential thrombocythemia

a Present Study

leading cause of maternal mortality in the developed world [35]. Pregnancy-associated VTE reflects the hypercoagulability that has evolved to protect women from hemorrhage at the time of childbirth or miscarriage [36]. The risk of VTE is highest immediately after delivery, specifically 3 to 6 weeks postpartum, after which the risk declines [37].

Obesity Obesity has been reported to be a risk factor for IVCT [38]. An increased pressure gradient between the thoracic and abdominal vena cava was found to be associated with a high body mass index $\left(>30 \mathrm{~kg} / \mathrm{m}^{2}\right)$, while two obese patients presented recurrent thrombosis [38].

Trauma Trauma-related IVCT were caused by a combination of various mechanisms [39]. Transmural laceration of the vena cava secondary to crushing forces, with formation of a pericaval hematoma, can compress and narrow the vena cava and cause venous stasis. Furthermore, endothelial injury of the venous wall may contribute to caval mural thrombosis [40]. Hepatic vein thrombosis with extension to IVC may occur if hepatic parenchyma is injured. In addition, hypercoagulability 
with suppression of fibrinolysis characterizes the physiological hemostatic responses after trauma while promotes IVCT.

\section{Provoked/secondary IVCT without outflow obstruction Lupus anticoagulants/anti-cardiolipin antibodies The presence of lupus anticoagulants and antiphospholipid syndrome have been revealed to be associated with IVCT [9]. Among patients with IVCT, 10.9 and $3.8 \%$ were reported to exhibit lupus anticoagulants and anti- cardiolipin antibodies, respectively [9]. Two studies reviewed computed tomography of patients with anti- phopholipid syndrome and reported IVCT in $8 / 12$ and 10/42 patients undergoing CT scan for suspected major abdominal vascular occlusion.[41, 42].}

Inferior vena cava filters and others Iatrogenic causes, such as an IVC filter, were found to be strongly associated with IVCT. The incidence of permanent filter-associated IVCT is approximately $13 \%$ after 8 years of follow-up [43]. Other etiologies associated with IVCT have been disclosed, including hereditary thrombophilia, paroxysmal nocturnal hemoglobinuria [44], pancreatitis [45], inflammatory disorders [46], oral contraceptives or hormonal replacement therapy [47], and coronavirus2019 (COVID19) infection [48], to mention a few. The risk of VTE is found to be increased significantly in the hospitalized COVID-19 patients, with an estimated incidence of $17 \%$ (12.1\% DVT and 7.1\% PE) [49]. Established mechanisms of VTE associated with COVID-19 include a hyperinflammatory response, platelet activation, and triggering of the coagulation cascade [50].

\section{Diagnosis}

Diagnosis of IVCT remains challenging at clinical presentation, which depended on the acuity level, extent of the thrombus, consequences of cava and/or splanchnic veins occlusion, and other accompanying VTE if present. Typical clinical features of IVCT include bilateral lower extremity DVT, scrotal swelling, unexplained back pain, pelvic pain, and in some cases, acute renal failure [51-54]. IVCT can present differently from lower-extremity DVT when IVCT also involves renal veins or hepatic veins. Renal vein involvement may result in flank pain and hematuria, whereas oliguria, anuria or uremia-related symptoms may indicate bilateral renal vein thrombosis. Hepatic vein involvement would compromise liver venous outflow, causing hepatic congestion, formation of ascites, and portal vein thrombosis. Chest pain and shortness of breath imply PE, which has been reported in $12 \%$ of patients with IVCT [2]. The following high risk features also strongly suggest to the diagnosis of IVCT, including the presence of an unretrieved IVC filter, iliofemoral DVT, bilateral DVT, unexplained new back pain or renal failure, known congenital IVC anomalies, severe PTS, renal cell carcinoma, and BCS [4]. Acute thrombosis at IVC with both iliofemoral veins involvement without collateral venous network may lead into phlegmasia cerulean dolen, which manifests with cyanosis and venous gangrene changes. Coagulation laboratory tests incorporating Ddimer, VTE probability evaluations, and thrombophilia screening would be valuable for the diagnosis of IVCT as well as DVT.

\section{Imaging assessment}

Multiple radiological modalities can be used to diagnose IVCT, including sonography, computed tomography, magnetic resonance imaging, and transcatheter venography. Sonography provides an accurate non-invasive evaluation and is often the first-line modality in investigating patients with lower extremity symptoms. Sonographic signs of IVCT include a monophasic Doppler waveform that does not synchronize with aspiratory rhythms and a "choppy" sign indicating increased blood velocity [55]. However, overlying bowel gas or body habitus can limit evaluations made by sonography. Contrast enhanced computed tomography with advances in 3D reconstruction allows clear depictions of the IVC structure and identifies the malignant nature of the thrombus [56]. Magnetic resonance imaging has advantages in delineating the presence, size and location of IVCT while avoiding radiation [57]. Catheterization of the IVC and hepatic veins can demonstrate patency or occlusion of the venous orifices.

\section{Treatment}

The objectives of IVCT treatment include reducing the risk of $\mathrm{PE}$, decreasing chronic complications such as PTS, and decreasing venous insufficiency and related symptoms. The cornerstone of IVCT management consists of in-time administration of anticoagulants, if not contraindicated. Unfractionated or low-molecularweight heparin is commonly used, followed by bridging to oral anticoagulants such as warfarin. Novel direct oral anticoagulant agents may be a reasonable alternative. While some may respond to anticoagulation only, up to $40 \%$ VTE patients reported thrombus propagation despite anticoagulation [58]. Additional treatment options depend on the acuity and severity of the thrombosis. Catheter-directed thrombolysis (CDT) alone or combined with pharmacomechanical thrombectomy have the advantages of rapid direct thrombolytic effects, which may reduce the risk of PTS complication for those with acute IVCT without high risk of bleeding [59], although not influencing the mortality significantly [60]. Urgent CDT is recommended for those patients with severe acute DVT associated with limb-threatening compromised or worsening IVCT despite anticoagulation [61]. 
The limitation of CDT is the potential increased risks of bleeding. Percutaneous transluminal angioplasty with a stent may be a reasonable choice for chronic thromobosis [62].

\section{Discussion}

This study is the first report that has examined IVCT presentation and characteristics in Taiwanese patients, amid the paucity of academic literature on the subject of IVCT. Our goals are to enhance and acknowledge awareness of the rare but liable to be neglected clinical conditions.

Clearly, this study has certain limitations. One of the major drawbacks was selective bias, since the information was gathered from limited patients in two hemophilia treatment and thrombosis centers within affiliated medical institutes in Taiwan. In addition, the collected information from a small number of patients was insufficient to reveal the overall picture of IVCT. Still, more in-depth information about IVCT as well as the results of large-scale investigations such as the SIVE CT (Study on Inferior Vena Cava Thrombosis) [63] are eagerly awaited. Nevertheless, our study has revealed several interesting findings that should be addressed.

First, our study highlighted that complete IVC thrombosis with bilateral lower extremity swelling (due to DVT) and abdominal wall superficial venous dilatation were present in four of our patients. This peculiar presentation can be regarded as a pathognomonic manifestation of complete IVCT, although it has been reported in only half of all IVCT patients [1,51]. It is plausible that once bilateral venous circulation from the lower extremities was compromised by complete IVC thrombosis, collateral circulation would ensue with resultant manifestations of superficial venous dilatation at the abdominal walls. This explanation is supported by the evidence that four partial IVCT patients in our study coexisted with only unilateral DVT.

In addition, all IVCT patients were found to have DVT in our study. The association between IVCT and VTE has been previously described. Congenital IVC anomalies or venous outflow obstruction/compression scenarios, such as BCS, have the capacity to elicit IVCT without precedent DVT, although not all of the precipitating conditions associated with IVCT were identified in our case series. Moreover, the thrombus formed from precedent DVT could propagate or extend into the IVC, wherein various known VTE risk factors could also contribute to IVCT.

Several thromboembolic risk factors were identified in our study. Notably, one of our patients with IVCT was found to have hemoglobin $\mathrm{H}$ disease, along with other risk factors, including pregnancy and an IVC filter. Hemoglobin $\mathrm{H}$ disease, also known as $\alpha$-thalassemia intermedia, has been identified as a hypercoagulable state with the demonstration of elevated thrombotic biomarkers [64, 65]. Abnormalities in pathologic red blood cells, activated platelets, endothelial damage, and splenectomy are established mechanisms of thalassemia that could contribute to VTE [66]. Although the association between thalassemia and IVCT has been reported sporadically [67], our findings suggest that the underlying hypercoagulable state of thalassemia may contribute to the development of IVCT, as well as other reported clinical thrombotic events.

One patient had ET. Venous thromboembolism and arterial thrombosis are the most common causes of morbidity and mortality in patients with MPNs, including ET [68]. Notably, thrombosis within the splanchnic or cerebral veins is a hallmark manifestation in patients with MPN [69]. The mechanisms of thrombotic potentials in MPN patients have been elaborated. They include increased blood counts, chronic inflammation, JAK-2 mutated endothelium, and aberrant plateletneutrophil interactions [70]. Advanced age ( $>60$ years), prior thrombosis, and the presence of the JAK2V617F mutation have been reported as substantial risk factors for predicting MPN-associated thrombosis [71].

The association between IVCT and MPN has been addressed. One study reported no evidence of this relationship, based on its retrospective analytic results showing that no MPN or JAK-2 V617F mutation was identified in a cohort of 40 enrolled IVCT patients [10]. However, we advocated different viewpoints by proposing that IVCT can be associated with MPN, as evidenced from our ET patient presenting with IVCT and from other previous observations [72, 73]. It is likely that not only the well-known prothrombotic potential of MPN can predispose to IVCT, but splanchnic vein thrombosis occurring in some MPN patients may also contribute, including portal vein thrombosis, mesenteric vein thrombosis, splenic vein thrombosis, or BCS. Further investigation on this issue is required to define the relationship between IVCT and MPNs.

Furthermore, three of our IVCT patients were found to carry lupus anticoagulants, while none carried anticardiolipin antibodies. Pregnancy, surgery, and antithrombin deficiency were also identified, which is consistent with the etiology of IVCT reported in other studies (Table 3). In particular, no known risk factors were identified in one patient, and she was classified as having idiopathic/primary IVCT. However, it should be noted that our retrospective description could not ascertain any occult or obscure predisposing factors.

Finally, our report disclosed that an unretrieved IVC filter was a risk factor for IVCT, as supported by the evidence that two patients developed IVCT after an IVC filter was not removed. Our results highlighted the 
emerging risk of IVCT in Taiwan as a complication following IVC filter placement, which corresponds to the accumulating evidence gathered from other Asian countries with a reported relatively lower risk of VTE [74-76].

The effectiveness of IVC filters in preventing PE in VTE patients remains controversial and inconclusive. According to the PREPIC study [77], an IVC filter was shown to have the potential benefit of protecting against short-term PE (at 12 days, $1.1 \%$ with $\mathrm{PE}$ in the filter group vs. $4.8 \%$ in the no-filter group, $p=0.03$ ). However, using IVC filters had a higher risk of symptomatic DVT in the long term (at 2 years, $20.8 \%$ in the filter group vs. $11.6 \%$ in the no-filter group, $p=0.02$ ), wherein the study showed no difference in the mortality rates during the 8year follow-up period [43]. Furthermore, according to the 2020 American Society of Hematology (ASH) guidelines for the management of venous thromboembolism [78], increased mortality and incidence of subsequent DVT were observed in patients using IVC filters. These guidelines present an evaluation of seven systemic reviews and two randomized trials, indicating low confidence in the evidence for IVC filter efficacy. A similar conclusion of insufficient evidence supporting IVC filter effectiveness was also reported from the National Institutes for Health and Care Excellence (NICE) review in 2020 [79].

The 2016 American College of Chest Physicians (ACCP) guidelines recommend the use of an IVC filter in patients with acute proximal DVT but in whom anticoagulants are contraindicated, such as those with active uncontrollable bleeding [80]. It is also considered reasonable for IVC filters to be used in thromboembolic patients in whom anticoagulation is perceived to have failed [81]. However, the ACCP advises against the initial use of an IVC filter in addition to anticoagulants in patients with acute DVT of the leg, which is primarily due to the efficacy and safety concerns regarding IVC filters [80]. A similar recommendation was also advocated by the ASH guidelines [78]. Moreover, a low retrieval rate after the placement of retrievable filters further aggravates realworld adverse event-related conditions [82].

Filter-related thromboembolism is a complicated process, which may be influenced by various filter types and designs, patient-specific underlying conditions, such as pregnancy or malignancy, and the intrinsic thrombogenicity of the device. This thrombogenicity is possible since a filter thrombus can be formed from the entrapped emboli within the filter. Furthermore, the filter could induce thrombus formation, as it is a foreign body. A thrombus could also be formed by DVTextension from the iliac and lower extremities veins. In our opinion, IVC filters should be implanted judiciously under absolute indications while the filter device application in clinical thrombotic conditions without approved indications, such as prophylactic use in patients without a history of PE, is strongly discouraged. Additionally, an implanted IVC filter must be retrieved whenever possible.

\section{Conclusions}

IVCT accounts for a substantial minority of DVT patients, although it is rare and liable to be underestimated. In accordance with venous thromboembolism, IVCT can be classified as either idiopathic/primary or provoked/secondary thrombosis, and various predisposing factors have been identified, including congenital IVC anomalies, malignancy, venous outflow obstruction/ compression scenarios, such as BCS or May-Thurner syndrome, as well as hereditary thrombophilia, acquired APS especially lupus anticoagulants, and other risk factors for VTE. IVC filter-related complication has become an emerging cause of IVCT, which was also highlighted in our case series. Acknowledgement of these clinical high-risk features, as well as the relevant presentations, such as bilateral lower extremity swelling, lower back/ pelvic pain, scrotum swelling, or PE, would help increase physicians' awareness of IVCT. Anticoagulant therapy is the cornerstone of IVCT treatment after diagnosis, while CDT strategies might offer additional advantages.

\section{Abbreviations \\ ACCP: American College of Chest Physicians; ASH: American Society of Hematology; BCS: Budd-Chiari syndrome; COVID-19: Coronavirus-2019; CDT: Catheter-directed thrombolysis; DVT: Deep venous thrombosis; ET: Essential thrombocythemia; FDA: Food and Drug Administration; IVC: Inferior vena cava; IVCT: Inferior vena cava thrombosis; MPN: Myeloproliferative neoplasm; NICE: National Institutes for Health and Care Excellence; PE: Pulmonary embolism; VTE: Venous thromboembolism}

\section{Acknowledgements}

Not applicable.

\section{Authors' contributions}

$\mathrm{HY}$ and CY collected and interpreted the patient data. MC proposed the study design and supervised the entire study process. HY was a major contributor to the writing of the manuscript. All authors have read and approved the final manuscript.

\section{Funding}

This research did not receive any specific grant from funding agencies in the public, commercial, or not-for-profit sectors.

Availability of data and materials

All data generated or analyzed during this study are included in this published article.

\section{Declarations}

Ethics approval and consent to participate

All patients provided informed consent to participate in this study, and the research was conducted in accordance with the Declaration of Helsinki. The study design was approved by the ethics review board of Changhua Christian Hospital. IRB No. 071014.

Consent for publication

All patients provided informed consent for the publication of this study. 


\section{Competing interests}

The authors declare that they have no competing interests.

Received: 27 December 2020 Accepted: 7 June 2021 Published online: 22 June 2021

\section{References}

1. McAree BJ, O'Donnell ME, Fitzmaurice GJ, Reid JA, Spence RA, Lee B. Inferior vena cava thrombosis: a review of current practice. Vasc Med. 2013;18(1):32-43.

2. Stein PD, Matta F, Yaekoub AY. Incidence of vena cava thrombosis in the United States. Am J Cardiol. 2008;102(7):927-9.

3. Lee LH, Gallus A, Jindal R, Wang C, Wu CC. Incidence of Venous Thromboembolism in Asian Populations: A Systematic Review. Thromb Haemost. 2017;117(12):2243-60

4. Alkhouli M, Morad M, Narins CR, Raza F, Bashir R. Inferior Vena Cava Thrombosis. JACC Cardiovasc Interv. 2016;9(7):629-43.

5. Agnelli G, Verso M, Ageno W, Imberti D, Moia M, Palareti G, et al. The MAST ER registry on venous thromboembolism: description of the study cohort. Thromb Res. 2008;121(5):605-10.

6. U.S. Food and Drug Administration, Inferior Vena Cava (IVC) Filters: Initial Communication: Risk of Adverse Events with Long Term Use (August 9, 2010)

7. U.S. Food and Drug Administration, Removing Retrievable Inferior Vena Cava Filters: FDA Safety Communication. (May 6, 2014).

8. Shi W, Dowell JD. Etiology and treatment of acute inferior vena cava thrombosis. Thromb Res. 2017:149:9-16.

9. Linnemann B, Schmidt H, Schindewolf M, Erbe M, Zgouras D, Grossmann R, et al. Etiology and VTE risk factor distribution in patients with inferior vena cava thrombosis. Thromb Res. 2008;123(1):72-8.

10. Linnemann B, Kraft C, Roskos M, Zgouras D, Lindhoff-Last E. Inferior vena cava thrombosis and its relationship with the JAK2V617F mutation and chronic myeloproliferative disease. Thromb Res. 2012;129(6):720-4.

11. Kraft C, Schuettfort G, Weil Y, Tirneci V, Kasper A, Haberichter B, et al. Thrombosis of the inferior vena cava and malignant disease. Thromb Res. 2014 Sep;134(3):668-73.

12. Teter $K$, Schrem E, Ranganath N, Adelman M, Berger J, Sussman R, et al. Presentation and Management of Inferior Vena Cava Thrombosis. Ann Vasc Surg. 2019;56:17-23.

13. Heit JA, Spencer FA, White RH. The epidemiology of venous thromboembolism. J Thromb Thrombolysis. 2016;41(1):3-14

14. Salgado Ordonez F, Gavilan Carrasco JC, Bermudez Recio FJ, Aguilar Cuevas R, Fuentes Lopez T, Gonzalez Santos P. Absence of the inferior vena cava causingrepeated deep venous thrombosis in an adult-a case report. Angiology. 1998;49(11):951-6.

15. Spentzouris G, Zandian A, Cesmebasi A, Kinsella CR, Muhleman M, Mirzayan $\mathrm{N}$, et al. The clinical anatomy of the inferior vena cava: a review of common congenital anomalies and considerations for clinicians. Clin Anat. 2014;27(8): 1234-43.

16. Truty MJ, Bower TC. Congenital anomalies of the inferior vena cava and left renal vein: implications during open abdominal aortic aneurysm reconstruction. Ann Vasc Surg. 2007;21(2):186-97.

17. Chee YL, Culligan DJ, Watson HG. Inferior vena cava malformation as a risk factor for deep venous thrombosis in the young. Br J Haematol. 2001 Sep; 114(4):878-80

18. Prado VE, Rey-Mendoza JP, Wakefield CJ, Aqeel SB, Kumssa A. Infrarenal inferior vena cava agenesis and recurrent deep vein thrombosis: a case report and literature review. Oxf Med Case Reports 2021;2021(1):omaa104.

19. Dean SM, Tytle TL. Acute right lower extremity iliofemoral deep venous thrombosis secondary to an anomalous inferior vena cava: a report of two cases. Vasc Med. 2006;11(3):165-9.

20. Fogg C, Serracino-Inglott F, Thachil J. Congenital absence of inferior vena cava: an overlooked cause of deep vein thrombosis. Br J Hosp Med (Lond) 2016:77(6):369.

21. Shafi I, Hassan AAl, Akers KG, Bashir R, Alkhouli M, Weinberger JJ, et al. Clinical and procedural implications of congenital vena cava anomalies in adults: A systematic review. Int J Cardiol 2020

22. Sevestre MA, Soudet S. Epidemiology and risk factors for cancer-associated thrombosis. J Med Vasc. 2020:45(6S):6S3-7.

23. Hartman DS, Hayes WS, Choyke PL, Tibbetts GP. From the archives of the AFIP. Leiomyosarcoma of the retroperitoneum and inferior vena cava: radiologic-pathologic correlation. Radiographics. 1992;12(6):1203-20.
24. Figueroa AJ, Stein JP, Lieskovsky G, Skinner DG. Adrenal cortical carcinoma associated with venous tumour thrombus extension. Br J Urol. 1997 Sep: 80(3):397-40.

25. Gotoh A, Gohji K, Fujisawa M, Okada H, Arakawa S, Hanioka K, et al. Renal angiomyolipoma associated with inferior vena caval tumour thrombus. Br J Urol. 1998 May:81(5):773-4.

26. Okuda K. Membranous obstruction of the inferior vena cava (obliterative hepatocavopathy, Okuda). J Gastroenterol Hepatol. 2001; 16(11):1179-83.

27. Okuda K, Kage M, Shrestha SM. Proposal of a new nomenclature for BuddChiari syndrome: hepatic vein thrombosis versus thrombosis of the inferior vena cava at its hepatic portion. Hepatology. 1998;28(5):1191-8.

28. Khan F, Armstrong MJ, Mehrzad H, Chen F, Neil D, Brown R, et al. Review article: a multidisciplinary approach to the diagnosis and management of Budd-Chiari syndrome. Aliment Pharmacol Ther. 2019:49(7):840-63.

29. Meng Y, Qin H, Ma Q, Zhang J, Zhang B, Pang H, et al. Deep vein thrombosis due to May-Thurner syndrome: a case report. BMC Cardiovasc Disord 2020;20(1):233-020-01515-Z.

30. Krywko DM, King KC. Aortocaval Compression Syndrome. StatPearls Treasure Island (FL): StatPearls Publishing LLC; 2020.

31. Humphries A, Mirjalili SA, Tarr GP, Thompson JMD, Stone P. Hemodynamic changes in women with symptoms of supine hypotensive syndrome. Acta Obstet Gynecol Scand. 2020 May;99(5):631-6.

32. Greer IA. CLINICAL PRACTICE. Pregnancy Complicated by Venous Thrombosis. N Engl J Med 2015;373(6):540-547.

33. Jerjes-Sanchez C, Rodriguez D, Farjat AE, Kayani G, MacCallum P, Lopes RD, et al. Pregnancy-Associated Venous Thromboembolism: Insights from GARFIELD-VTE. TH Open 2021;5(1):e24-e34.

34. Nichols KM, Henkin S, Creager MA. Venous Thromboembolism Associated With Pregnancy: JACC Focus Seminar. J Am Coll Cardiol 2020;76(18):2128-2141.

35. Marik PE, Plante LA. Venous thromboembolic disease and pregnancy. N Engl J Med. 2008;359(19):2025-33.

36. James $\mathrm{AH}$. Venous thromboembolism in pregnancy. Arterioscler Thromb Vasc Biol. 2009;29(3):326-31.

37. Kamel H, Navi BB, Sriram N, Hovsepian DA, Devereux RB, Elkind MS. Risk of a thrombotic event after the 6-week postpartum period. N Engl J Med 2014 370(14):1307-1315.

38. Linicus Y, Kindermann I, Cremers B, Maack C, Schirmer S, Bohm M. Vena cava compression syndrome in patients with obesity presenting with edema and thrombosis. Obesity (Silver Spring). 2016;24(8):1648-52.

39. Chakroun A, Nakhli MS, Kahloul M, Harrathi MA, Naija W. Post traumatic inferior vena cava thrombosis: A case report and review of literature. Int J Surg Case Rep. 2017;36:59-63.

40. Kim KY, So BJ, Park DE. Management of inferior vena cava thrombosis after blunt liver injury. Korean J Hepatobiliary Pancreat Surg. 2014;18(3):97-100.

41. Kim JH, Ha HK, Yoon KH, Lee YS, Park KB, Lee IJ, et al. CT features of abdominal manifestations of primary antiphospholipid syndrome. J Comput Assist Tomogr. 1999:23(5):678-83.

42. Kaushik S, Federle MP, Schur PH, Krishnan M, Silverman SG, Ros PR. Abdominal thrombotic and ischemic manifestations of the antiphospholipid antibody syndrome: CT findings in 42 patients. Radiology. 2001;218(3):768-71.

43. PREPIC Study Group. Eight-year follow-up of patients with permanent vena cava filters in the prevention of pulmonary embolism: the PREPIC (Prevention du Risque d'Embolie Pulmonaire par Interruption Cave) randomized study. Circulation. 2005;112(3):416-22.

44. Malik I, Bhatia V, Kumar K, Sibal A, Goyal N. Pediatric Hepatic Venous Outflow Tract Obstruction: Experience from a Transplant Center. Indian Pediatr 2019;56(11):965-967.

45. Herath HM, Kulatunga A. Acute pancreatitis complicated with deep vein thrombosis and pulmonary embolism: a case report. J Med Case Rep 2016 23:10(1):182-016-0968-6.

46. Cheng K, Faye AS. Venous thromboembolism in inflammatory bowel disease. World J Gastroenterol 2020:26(12):1231-1241.

47. Sitruk-Ware R. Hormonal contraception and thrombosis. Fertil Steril. 2016; 106(6):1289-94.

48. Sh Hassan AA, Alsaleh ME, Alsaleh ME, Al Zaher FA, Almajed FA, Alkhudhair AM, et al. Budd-Chiari Syndrome: A Case Report of a Rare Presentation of COVID-19. Cureus 2021;13(1):e12554.

49. Jimenez D, Garcia-Sanchez A, Rali P, Muriel A, Bikdeli B, Ruiz-Artacho P et al. Incidence of VTE and Bleeding Among Hospitalized Patients With 
Coronavirus Disease 2019: A Systematic Review and Meta-analysis. Chest 202017.

50. Moschonas IC, Tselepis AD. SARS-CoV-2 infection and thrombotic complications: a narrative review. J Thromb Thrombolysis 2021.

51. Jackson BT, Thomas ML. Post-thrombotic inferior vena caval obstruction. A review of 24 patients. Br Med J 1970;1(5687):18-22.

52. Kraft C, Hecking C, Schwonberg J, Schindewolf M, Lindhoff-Last E, Linnemann B. Patients with inferior vena cava thrombosis frequently present with lower back pain and bilateral lower-extremity deep vein thrombosis. Vasa. 2013;42(4):275-83.

53. Ahmed M, Saeed R, Abdulsalam M, Johna S, Elias D. Inferior Vena Cava Calcified Thrombus Presenting With Abdominal Pain: A Case Report. Cureus 2019 13;11(8):e5384.

54. McAree BJ, O'Donnell ME, Boyd C, Spence RA, Lee B, Soong CV. Inferior vena cava thrombosis in young adults-a review of two cases. Ulster Med J 2009 May; 78(2):129-133.

55. Park JH, Lee JB, Han MC, Choi BI, Im CK, Chang KH, et al. Sonographic evaluation of inferior vena caval obstruction: correlative study with vena cavography. AJR Am J Roentgenol. 1985;145(4):757-62.

56. Sheth S, Fishman EK. Imaging of the inferior vena cava with MDCT. AJR Am J Roentgenol. 2007;189(5):1243-51.

57. Soler R, Rodriguez E, Lopez MF, Marini M. MR imaging in inferior vena cava thrombosis. Eur J Radiol. 1995;19(2):101-7.

58. Kearon C, AkI EA. Duration of anticoagulant therapy for deep vein thrombosis and pulmonary embolism. Blood 2014;123(12):1794-1801.

59. Ye K, Qin J, Yin M, Liu X, Lu X. Outcomes of Pharmacomechanical Catheterdirected Thrombolysis for Acute and Subacute Inferior Vena Cava Thrombosis: A Retrospective Evaluation in a Single Institution. Eur J Vasc Endovasc Surg. 2017:54(4):504-12.

60. Alkhouli M, Zack CJ, Zhao H, Shafi I, Bashir R. Comparative outcomes of catheter-directed thrombolysis plus anticoagulation versus anticoagulation alone in the treatment of inferior vena caval thrombosis. Circ Cardiovasc Interv. 2015;8(2):e001882

61. Mewissen MW, Seabrook GR, Meissner MH, Cynamon J, Labropoulos N, Haughton SH. Catheter-directed thrombolysis for lower extremity deep venous thrombosis: report of a national multicenter registry. Radiology. 1999;211(1):39-49.

62. Partovi S, Kalva SP, Walker TG, Taj SM, Ganguli S. Long term follow-up of endo-vascular recanalization of chronic inferior vena cava occlusion secondary to inferior vena cava filters. Vasa 2017:46(2):121-126.

63. Cohen O. Study on Inferior Vena Cava Thrombosis (SIVECT) - Full Text View - ClinicalTrials.gov. https://clinicaltrials.gov/ct2/show/NCT04470986. Accessed 17 May 2021

64. Sirachainan N. Thalassemia and the hypercoagulable state. Thromb Res. 2013;132(6):637-41.

65. Chansai S, Fucharoen S, Fucharoen G, Jetsrisuparb A, Chumpia W. Elevations of Thrombotic Biomarkers in Hemoglobin H Disease. Acta Haematol. 2018; 139(1):47-51.

66. Succar J, Musallam KM, Taher AT. Thalassemia and venous thromboembolism. Mediterr J Hematol Infect Dis. 2011;3(1):e2011025.

67. Prajantasen T, Teawtrakul N, Fucharoen G, Fucharoen S. Molecular characterization of a beta-thalassemia intermedia patient presenting inferior vena cava thrombosis: interaction of the beta-globin erythroid Kruppel-like factor binding site mutation with $\mathrm{Hb} \mathrm{E}$ and alpha(+)-thalassemia. Hemoglobin. 2014;38(6):451-3.

68. Hultcrantz M, Bjorkholm M, Dickman PW, Landgren O, Derolf AR, Kristinsson SY, et al. Risk for Arterial and Venous Thrombosis in Patients With Myeloproliferative Neoplasms: A Population-Based Cohort Study. Ann Intern Med 2018:168(5):317-325.

69. How J, Zhou A, Oh ST. Splanchnic vein thrombosis in myeloproliferative neoplasms: pathophysiology and molecular mechanisms of disease. Ther Adv Hematol 2017;8(3):107-118.

70. Reeves BN, Beckman JD. Novel Pathophysiological Mechanisms of Thrombosis in Myeloproliferative Neoplasms. Curr Hematol Malig Rep 2021.

71. Barbui T, Finazzi G, Carobbio A, Thiele J, Passamonti F, Rumi E, et al. Development and validation of an International Prognostic Score of thrombosis in World Health Organization-essential thrombocythemia (IPSETthrombosis). Blood 2012;120(26):5128-33; quiz 5252.

72. Randi ML, Putti MC, Fabris F, Sainati L, Zanesco L, Girolami A. Features of essential thrombocythaemia in childhood: a study of five children. $\mathrm{Br} J$ Haematol. 2000;108(1):86-9.
73. Foresti V, Ungaro A, Pediconi AM. Budd-Chiari syndrome secondary to thrombosis of the inferior vena cava in myeloproliferative disease. Minerva Med. 1988;79(6):477-80.

74. Yamashita Y, Unoki T, Takagi D, Hamatani Y, Ishii M, Iguchi M, et al. Indications, applications, and outcomes of inferior vena cava filters for venous thromboembolism in Japanese patients. Heart Vessels. 2016;31(7): 1084-90.

75. Park H, Han A, Choi C, Min SI, Ha J, Jung IM, et al. Current Status of the Retrieval Rate of Retrievable Vena Cava Filters in a Tertiary Referral Center in Korea. Vasc Specialist Int. 2014;30(4):133-8.

76. Pan Y, Zhao J, Mei J, Shao M, Zhang J, Wu H. Retrievable Inferior Vena Cava Filters in Trauma Patients: Prevalence and Management of Thrombus Within the Filter. Eur J Vasc Endovasc Surg. 2016;52(6):830-7.

77. Decousus H, Leizorovicz A, Parent F, Page Y, Tardy B, Girard P, et al. A clinical trial of vena caval filters in the prevention of pulmonary embolism in patients with proximal deep-vein thrombosis. Prevention du Risque d'Embolie Pulmonaire par Interruption Cave Study Group. N Engl J Med 1998;338(7):409-415

78. Ortel TL, Neumann I, Ageno W, Beyth R, Clark NP, Cuker A, et al. American Society of Hematology 2020 guidelines for management of venous thromboembolism: treatment of deep vein thrombosis and pulmonary embolism. Blood Adv 2020:4(19):4693-4738.

79. Schulman S, Konstantinides S, Hu Y, Tang LV. Venous Thromboembolic Diseases: Diagnosis, Management and Thrombophilia Testing: Observations on NICE Guideline [NG158]. Thromb Haemost. 2020;120(8):1143-6.

80. Kearon C, Akl EA, Ornelas J, Blaivas A, Jimenez D, Bounameaux H, et al. Antithrombotic Therapy for VTE Disease: CHEST Guideline and Expert Panel Report. Chest. 2016;149(2):315-52

81. Jaff MR, McMurtry MS, Archer SL, Cushman M, Goldenberg N, Goldhaber SZ, et al. Management of massive and submassive pulmonary embolism, iliofemoral deep vein thrombosis, and chronic thromboembolic pulmonary hypertension: a scientific statement from the American Heart Association. Circulation 2011;123(16):1788-1830

82. Mohapatra A, Liang NL, Chaer RA, Tzeng E. Persistently low inferior vena cava filter retrieval rates in a population-based cohort. J Vasc Surg Venous Lymphat Disord. 2019;7(1):38-44.

\section{Publisher's Note}

Springer Nature remains neutral with regard to jurisdictional claims in published maps and institutional affiliations.
Ready to submit your research? Choose BMC and benefit from:

- fast, convenient online submission

- thorough peer review by experienced researchers in your field

- rapid publication on acceptance

- support for research data, including large and complex data types

- gold Open Access which fosters wider collaboration and increased citations

- maximum visibility for your research: over $100 \mathrm{M}$ website views per year

At BMC, research is always in progress.

Learn more biomedcentral.com/submissions 